\section{O negacionismo enquanto política: o debate da cloroquina em uma comissão parlamentar}

Denialism as policy: the debate on chloroquine in a congressional inquiry in Brazil

El negacionismo como política: el debate de la cloroquina en una comisión parlamentaria
Thais Rodrigues Penaforte 1

doi: 10.1590/0102-311X00023021

\section{Resumo}

O objetivo deste trabalho foi esclarecer os movimentos e desdobramentos sobre a politica terapêutica da cloroquina, no Parlamento brasileiro, a fim de identificar os fatores que a situaram no contexto da ação pública contra a COVID-19. Os artefatos etnográficos utilizados para essa análise incluíram as videoconferências das reuniões e audiências públicas e as notas taquigráficas disponíveis publicamente no site da Câmara dos Deputados. Como resultado, observou-se que o debate da cloroquina foi forjado entre as evidencias científicas utilizadas a partir de uma perspectiva negacionista, que privilegiou a busca pela incerteza como forma de produzir dissenso e assim sustentar convicções pessoais e ideologias. Ao rejeitarem proposições empiricamente sustentadas e o próprio consenso científico, buscou-se criar uma falsa aparência de debate. O objetivo era criar o convencimento de que não há motivos suficientes para rejeitar o uso da cloroquina como terapêutica para a COVID-19. Desse modo, o êxito logrado pelo governo não ocorreu a partir da verificação de verdades, mas foi o resultado de uma acomodação contingencial que estabilizou esse fato não em meio a certezas, mas pelo medo da dúvida.

Política Pública; Política de Saúde; COVID-19; Cloroquina
Correspondência

T. R. Penaforte

Universidade Federal da Bahia.

Rua Barão de Jeremoabo 147, Salvador, BA 40170-115, Brasil. thaisrpenaforte@gmail.com

1 Universidade Federal da Bahia, Salvador, Brasil. 


\section{Introdução}

O novo coronavírus (SARS-CoV-2) instalou, mundialmente, o cenário que há décadas a comunidade da saúde pública temia: a emergência de um vírus perigoso, pouco conhecido e de elevada transmissibilidade 1. A dinâmica da COVID-19, ao irromper uma crise sanitária sem precedentes, exigiu de chefes de estado e governos subnacionais maior afinco na criação de regulamentações e políticas públicas ágeis e precisas, capazes de instrumentalizar a ação governamental para o enfrentamento e a minimização de seus efeitos. No entanto, com um cenário incontido, essa pandemia tem produzido efeitos que não se restringem ao seu lastro sanitário. Sua repercussão no meio econômico, social e na geopolítica mundial tem recuperado a transcendência da saúde sobre os domínios da vida. E considerando o atual cenário político nacional, de ascensão da extrema direita, exacerbada polarização e retrocessos sociais, a assistência à saúde se vê deturpada em sua natureza, sendo operada e justificada contrariamente às conquistas erigidas pelo Sistema Único de Saúde.

Garantida pela Constituição Federal de 1988 como direito social, a saúde deve ser provida pelo Estado, mediante o ordenamento de políticas públicas. Portanto, cabe ao poder público a regulação das condições indispensáveis para o seu pleno exercício ${ }^{2}$. No intuito de se programar para os efeitos e necessidades da sociedade durante a crise da COVID-19, a Lei no 13.979, de 6 de fevereiro de 2020, foi o primeiro marco legal a estabelecer as bases para a proteção da coletividade 3. E, a partir dessa lei, uma comissão temporária foi criada - a Comissão Externa da Câmara dos Deputados destinada a acompanhar o enfrentamento à pandemia da COVID-19 no Brasil (CEXCORVI). Instituída pelo Presidente da Câmara, a partir de dois requerimentos independentes, apresentados pelos parlamentares: Dr. Luiz Antonio Teixeira Jr. (PP-RJ) e Carmen Zanotto (Cidadania-SC), essa comissão foi constituída com a finalidade de "aproximar o Parlamento das ações desenvolvidas pelo Poder Executivo para conter uma possivel disseminação do surto [da COVID-19] em território nacional" 4. E concentrando a tramitação e o debate das principais medidas legais dirigidas ao enfrentamento da pandemia da COVID-19, essa comissão tem ocupado um lugar relevante na definição das ações públicas contra essa crise sanitária.

$\mathrm{Na}$ articulação para fazer frente ao avanço da pandemia, diversas medidas foram dedicadas à saúde pública. No entanto, nenhuma causou tamanha controvérsia como a incorporação da cloroquina como orientação terapêutica pelo Ministério da Saúde. E considerando que a maneira pela qual políticas governamentais são aprovadas e implementadas, revelam condições de poder e função, é preciso compreender as políticas públicas como programas de ação, que representam os meios concretos pelos quais o Estado expressa sua vontade de modificar comportamentos, mediante a alteração das regras do jogo até então operantes 5 .

O lugar da cloroquina no tratamento da COVID-19 ilustra a problemática do processo de formulação de políticas públicas em um ambiente de democracia e participação, que convive com enormes desigualdades sociais que demandam por solução ${ }^{6}$. Ao mesmo tempo, esse cenário evidencia a indissociabilidade entre ciência e política, revelando o quanto esses campos estão intimamente implicados. Como afirma Latour 7 (p. 18), "sem os instrumentos da ciência, o corpo político jamais saberá quantas entidades desconhecidas é preciso levar em consideração". Por isso, as conexões entre esses campos devem ser cuidadosamente analisadas, esclarecendo como ciência e política exercem suas tarefas de definir quantas e quais entidades devem ser consideradas 7,8 .

O interesse deste trabalho se dirige aos movimentos e desdobramentos sobre a política terapêutica da cloroquina, com o objetivo de identificar e delimitar essa proposta no Parlamento brasileiro. E na busca pelo espaço privilegiado e autoritativo desse debate, nos dirigimos à CEXCORVI com seus múltiplos atores, posturas e interesses. Considerando que, como afirma Latour 9 (p. 65, grifo da autora), "não são as atitudes que contam em política, mas a forma e o peso do mundo aos quais essas atitudes têm por função responder".

\section{A CEXCORVI}

O processo legislativo compreende as regras e os procedimentos que envolvem a produção de leis. E, no âmbito do Poder Legislativo, cabe às comissões o exame circunstanciado de todas as proposições que tramitam em cada uma das casas do Congresso Nacional. Estruturados como órgãos compostos 
por um número reduzido de parlamentares e seguindo a proporcionalidade partidária, seu processo de trabalho inclui a realização de audiências públicas com entidades da sociedade civil, ministros de Estado e outras autoridades, podendo ainda ter competência plena para aprovar projetos de lei sem necessidade de manifestação do Plenário 10.

Instituída em 11 de fevereiro de 2020, inicialmente, a comissão era composta por dez deputados. Desde então, novas designações foram aditadas, e, com referência ao período estudado, o arranjo político da comissão foi formado por 20 deputados, a maior parte com experiência na assistência à saúde e/ou gestão de serviços de saúde e/ou pesquisa científica. Sua disposição profissional incluiu médicos (10), advogados (4), policial (1), corretor (1), enfermeira (1), engenheira (1), administrador (1) e servidor público (1). A maioria inaugurava seu primeiro mandato $(55 \%, 11 / 20)$ e participava concomitantemente de outras comissões ou frentes parlamentares relacionadas à saúde.

No processo de produção de políticas públicas para a COVID-19 pelo Poder Legislativo, a CEXCORVI se consolidou como um espaço privilegiado, podendo ser identificada como um subsistema de política. Essas subunidades do sistema político possuem organização dinâmica, e seus participantes desenvolvem experiência política e relacionamentos mútuos a partir de arenas de interesse direto. E por serem especialistas em uma questão particular, esses atores possuem considerável independência no desenvolvimento, implementação e avaliação de políticas que estão sob a jurisdição de determinado subsistema 11,12.

Para Thurber 12, os subsistemas políticos são uma forma de representação funcional decorrente da divisão do trabalho e do desenvolvimento de conhecimentos especializados na sociedade. E como no contexto das políticas de saúde, a categoria médica, por meio de suas inter-relações com o Estado, tradicionalmente, desempenha um papel preponderante nos processos de criação e implementação de políticas públicas, não é inesperado que essa confluência de interesses venha a se reproduzir em uma comissão, cuja função é balizar o desenho do Programa Brasileiro para Enfrentamento da Pandemia da COVID-19.

E se estamos na busca dos fatores que situam a cloroquina no contexto da ação pública contra a COVID-19 e que ilustram como o sistema político produz políticas públicas, é preciso esclarecer o papel e a atuação desses atores. Especialmente por considerarmos que é a própria relação entre os membros, o compartilhamento e a coesão de valores, somado ao domínio técnico e legal sobre políticas específicas, que legitimam a atuação e o processo decisório de determinado grupo político.

\section{Metodologia}

Os encontros etnográficos deste trabalho foram conduzidos por vídeos e documentos, e, por meio desses, foi possível enxergar as pessoas, a engrenagem da CEXCORVI e do próprio Estado sobre a temática da cloroquina no tratamento da COVID-19 13.

A investigação sobre o processo de consolidação dessa política pública se ocupou de uma comissão parlamentar como unidade de análise - a CEXCORVI. Concentrando a atenção na atuação e configuração de seus atores e demais entidades participantes, buscou-se examinar a dinâmica desse subsistema político.

Em 22 reuniões, que ocuparam o período de 18 de março a 19 de agosto de 2020, a temática da cloroquina foi debatida nessa comissão, com destaque aos dias 22 de abril e 14 de julho que funcionaram como verdadeiros “Tribunais da Cloroquina”. Pois como descreve Latour 8 , quando um elemento de interesse entra no seio de uma assembleia, isso exige que também um julgamento seja levado em comum.

Ainda segundo o autor, considerando que as questões de fato são versões parciais, polêmicas e políticas das questões de interesse, essas devem ser descritas como um estado das coisas 14. Por isso, a tarefa analítica deste trabalho não foi desmascarar atores ou argumentos, mas compreender seu processo de construção e agregação. Isso exigiu o acompanhamento de todas as entidades envolvidas no fenômeno da cloroquina esclarecendo suas combinações e interações, que compuseram esse antagônico campo de forças. E a fim de descrever como se projetavam essas redes de influência, conhecimento e poder, adotou-se o conceito de Coalizões de Defesa de Sabatier \& Weible 15 como abordagem compreensiva desse interjogo político. 
O modelo das coalizões de defesa foi originalmente desenvolvido para explicar o processo de mudança nas políticas públicas dentro de um determinado sistema político ou arranjo institucional, em um longo período. Desenhado para lidar com problemas ardilosos, sua estrutura confere maior peso aos sistemas de crença que à afiliação institucional para a definição dos objetivos individuais. Além de considerar que, dada a complexidade do ambiente de formulação de políticas nas sociedades modernas, é preciso que seus participantes se especializem em segmentos específicos a fim de obter poder e influência.

Como corpus de pesquisa, servimo-nos de narrativas, documentos científicos e medidas legislativas, que foram obtidos junto às videoconferências e notas taquigráficas, disponíveis publicamente no site da Câmara dos Deputados. Todo o material empírico foi explorado utilizando-se o software Atlas.ti (http://atlasti.com/), que contribuiu para a composição e interpretação dos dados. Na etapa de análise, procedeu-se à categorização por codes em que se buscou destacar: os elementos capazes de caracterizar a ação dos atores, situar seus discursos, suas montagens projetadas e a atuação dos intermediários decisivos que forjaram os múltiplos estádios da cloroquina.

No curso analítico deste trabalho, atentamo-nos a todos os participantes da comissão (humanos e não humanos) e como seu desempenho fomentou convicções e crenças que se traduziram em apoio ou não à política terapêutica da cloroquina. Assim, subdividindo esse subsistema em duas grandes coalizões: uma a favor e outra contrária ao uso da cloroquina no tratamento da COVID-19, aproximamo-nos do desenho de cada conjunto de crenças e como essas dirigiram o debate político.

\section{Resultados}

\section{Política e medicina na ascensão da cloroquina}

Com uma composição dominada por deputados médicos (contabilizando a participação regular, dos 14 deputados mais assíduos, 71,4\% [10/14] eram médicos), esses atores reproduziam, no âmbito legislativo, seus próprios imperativos. Assim, não apenas o processo legislativo se estruturou nessas bases, como também a profissão médica foi definida como a mais habilitada a ocupar esse espaço.

“(...) eu acho que esta Comissão, neste momento, tem muito peso político na Casa, pois é a Comissão que reúne aqui as pessoas do campo da saúde. É assim que ela está sendo vista pela Casa e, por isso, tem peso junto à Presidência, junto à tramitação de matérias" (Deputada Jandira Feghali, PCdoB-RJ, 09/Abr/2020).

A primeira atitude dos deputados na busca por soluções terapêuticas para a pandemia foi o rastreamento da literatura médica, adotando a abordagem da Saúde Baseada em Evidências (SBE). Consolidada como uma extensão da Medicina Baseada em Evidências (MBE), a SBE diz respeito à gestão do cuidado em saúde tomado a partir das melhores e mais atuais evidências derivadas de estudos populacionais 16 . Os primeiros estudos a serem citados na comissão foram as pesquisas conduzidas como os medicamentos Favipiravir (Avigan) e o Remdesivir (Veklury). E mesmo com uma liberação pelo órgão regulador da Agência Americana de Controle de Alimentos e Medicamentos (FDA, em inglês), a postura era de cautela, a fim de aguardar uma confirmação conclusiva que só poderia ser alcançada com a finalização dos estudos.

A grande movimentação em torno da cloroquina só ocorreu com a publicação de um tweet do presidente Donald Trump em 21 de março de 2020 17. Inspirado em um preprint datado de 20 março (e publicado apenas em julho de 2020) de Gautret et al. 18, o líder estadunidense sugeriu que a combinação hidroxicloroquina e azitromicina seria a chance real de superação da pandemia. Logo em seguida, o presidente brasileiro Jair Bolsonaro, em 27 de março 2020, afirmou que: "temos informações precisas que a cloroquina tem sido usada pelo Brasil com uma grande taxa de sucesso” 19.

Ao atualizar a comissão sobre as ações nacionais para enfrentamento da COVID-19, o Coronel Chrisóstomo (PSL-RO) foi o primeiro a indicar as ações governamentais em relação à cloroquina, informando que o Exército brasileiro estava fabricando esse medicamento em seus laboratórios para serem distribuídos Brasil afora.

"Isso é algo sobre o que não temos ouvido falar, nobre Deputada, mas o Exército brasileiro está fazendo isso, está executando isso. Agora há militares fabricando cloroquina para enviar para Estados e Municípios. Sem 
dúvida nenhuma é um belíssimo trabalho das Forças Armadas e do Exército brasileiro" (Deputado Coronel Chrisóstomo, PSL-RO, 09/Abr/2020).

Essas informações indicavam o interesse do Executivo em regular uma política terapêutica para a COVID-19. E em vista disso, a comissão foi imediatamente acionada para deliberar sua posição acerca do tema. O primeiro passo tomado para a construção de posição dos deputados foi a convocação de audiências com pesquisadores e especialistas. E já preparando o debate para uma investida negacionista e a construção de um cenário com dois lados definidos a partir de uma questão de opinião, a exigência por uma pluralidade de posições foi logo acionada:

"Então, que nessa segunda audiência pública sobre as opções terapêuticas talvez pudéssemos ouvir dois infectologistas: um a favor e um contra drogas como cloroquina, hidroxicloroquina e outras" (Deputada Dra. Soraya Manato, PSL-ES, 15/Abr/2020).

Nos primeiros debates, a crítica não se dirigia ao uso em si da cloroquina, mesmo na situação de indicações científicas frágeis, mas, à ruptura do protocolo cerimonial da SBE, ao descumprir com a hierarquia de decisão.

"Numa situação dramática como esta, e acho que todos os pesquisadores falaram sobre isto, é muito comum começar a haver uso de várias terapias sem comprovação científica sólida. (...) Somos atores políticos precisamos ter, antes de mais nada, profunda humildade de ouvir a ciência. A última opinião que eu pude dar mais firme e sem ouvir foi no último ensaio clínico de que participei como coordenador, há 14 anos, em 2005” (Deputado Padilha, PT-SP, 22/Abr/2020).

"Não é assim! Tem que haver um grupo de cientistas fazendo estudos, como os que estão sendo feitos (...). Os ensaios clínicos são fundamentais. Hoje aqui está sendo dito que deve haver uma voz, pelo menos da maioria dos cientistas do Brasil, sobre o que se vai fazer na condução desses processos" (Deputado Pedro Westphalen, Bloco/PP-RS, 22/Abr/2020).

Os discursos indicavam que, no primeiro momento, o governo assentia à decisão das organizações científicas e profissionais, construindo um trabalho conjunto e que se consolidava como uma decisão técnica. Ao romper com esse fluxo de poder e insurgir em um voo solo, o Executivo se distanciou da ciência e, consequentemente, das "boas decisões".

"Apoiamos o Ministro Luiz Henrique Mandetta e o Presidente Bolsonaro, naquele primeiro momento em que houve uma tentativa de expansão do sistema de saúde com medidas de isolamento e de higienização; como apoiamos também, agora, o Ministro Nelson Teich, porque entendemos que este é o momento em que todos temos que estar unidos. (...) Em relação às competências legais do Conselho Federal de Medicina, cabe à nossa instituição determinar o que é experimental e o que não é experimental para o Brasil" (Mauro Luiz de Britto Ribeiro, CFM - Conselho Federal de Medicina, 22/Abr/2020).

No entanto, rebatendo as acusações de ter tomado decisões monocráticas, o próprio governo se defende, argumentando estar em total concordância com as disposições do CFM:

"O documento elaborado pelo Ministério traz uma orientação justamente para esse médico assistente, que ficou liberado, ou seja, ele não está proibido, pois o próprio Conselho estabeleceu isso. Então, é uma determinação do parecer do Conselho Federal de Medicina. O Ministério tem a obrigação de orientar, de regulamentar como é feito esse uso, uma vez que o médico não está proibido (...) Mas, se o próprio Conselho Federal de Medicina estabelece esse critério, qual deve ser o posicionamento do Ministério frente a essa situação?" (Wanderson Oliveira, Ministério da Saúde, 20/Mai/2020).

E salienta não ter produzido protocolos ou diretrizes terapêuticas, mas apenas notas técnicas informativas, que visavam dar proteção institucional aos prescritores que já vinham adotando essa conduta terapêutica sem nenhum respaldo governamental.

“As orientações para atendimento precoce - não é protocolo, são orientações (...). Simplesmente faculta-se ao profissional de saúde que, dentro da sua autonomia, prescreva um medicamento que está disponibilizado pelo SUS, dentre eles a cloroquina" (Elcio Franco, Ministério da Saúde, 09/Jul/2020).

Entretanto, a partir dessa sinalização institucional, prescritores, usuários e a própria cloroquina alcançaram legitimação, o que possibilitou a incorporação de novos arranjos terapêuticos. Inicialmente, ainda na gestão do Ministro Henrique Mandetta (01/Jan/2019-16/Abr/2020), a Nota Informativa $n^{o}$ 6/2020-DAF/SCTIE/MS, de 1o de abril de 2020, instituiu o uso compassivo da cloroquina "como terapia adjuvante no tratamento de formas graves, em pacientes hospitalizados, sem que outras medidas de suporte sejam preteridas em seu favor" 20 . Durante o período de interinidade no Ministério da Saúde, entre a saída de Nelson Teich (14/Abr/2020-15/Mai/2020) e a posse de Eduardo Pazuello (02/Jun/2020-23/ 
Mar/2021), foi publicada, em 20 de maio de 2020, a Nota Informativa no 9/2020 - SE/GAB/SE/MS 21, com orientações para manuseio medicamentoso precoce de pacientes com diagnóstico de COVID-19, indicando o uso de cloroquina já na presença de sinais e sintomas leves. Um dos desdobramentos dessa diretriz foi a popularização de kits COVID - uma combinação dos medicamentos cloroquina ou hidroxicloroquina, ivermectina, azitromicina e doxiciclina - sendo esse o esquema terapêutico para tratamento precoce da COVID-19, oferecido pela plataforma digital TrateCOV do governo federal e que contou com forte apoio e estímulo do Ministério da Saúde 22.

\section{A política terapêutica da COVID-19 e os valores da ciência}

Em duas reuniões, o debate acerca da indicação ou não da cloroquina como diretriz terapêutica foi mais destacado. A primeira, em 22 de abril de 2020, versou sobre as opções terapêuticas para a COVID-19 e contou com a presença de dez convidados e 12 deputados. Entre os convidados, dois representavam organizações médicas profissionais, seis estavam ligados a organizações hospitalares e/ou de pesquisa, e dois eram representantes da Secretaria de Ciência, Tecnologia e Insumos Estratégicos (SCTIE) do Ministério da Saúde . Dentre esse grupo, dois apresentaram posições favoráveis ao uso da cloroquina no tratamento da COVID-19, quatro eram contrários a esse uso, dois não se manifestaram, e dois se posicionaram de maneira dúbia, aguardando os resultados de novos estudos clínicos. Entre os deputados, dois se posicionaram favoravelmente ao uso da cloroquina, dois foram contrários, quatro não se manifestaram sobre o assunto, e quatro demonstram posição indefinida também no aguardo de mais estudos.

A segunda reunião sobre o tema teve como pauta o tratamento precoce para a COVID-19 e ocorreu em 14 de julho de 2020. Contou com 11 convidados, sendo: dois médicos (um prefeito e outro membro de Comitê Científico Municipal), sete participavam de organizações hospitalares e/ou de pesquisa, e dois eram representantes da SCTIE. Desses, cinco eram favoráveis ao uso da cloroquina, e seis, contrários. Entre os seis deputados presentes, três eram favoráveis ao uso da cloroquina; dois, contrários e um permaneceu sem posição definida. Deste grupo, um deputado modificou sua posição desde a primeira reunião (em 22 de abril). Anteriormente com uma posição indefinida, nesta, o deputado passou a se posicionar de maneira favorável ao uso da cloroquina.

Destaca-se que o debate da cloroquina foi forjado a partir de evidências científicas que funcionaram ao mesmo tempo como: (a) parâmetro opinativo; (b) estratégia e guia para a tomada de posição; e (c) sistema de valores que oportunizam as coalizões (Figura 1).

O sistema de crenças dos atores (Figura 2) revela formas de relacionamento com esse paradigma que repercutem em operações e filtros de percepção que forjam verdades e interpretações. Essas operações determinaram posições e estratégias que são fundamentais para a formação de autoridade e fortalecimento da coalizão, preenchendo lacunas que impediam o avanço de posições. Ao mesmo tempo, esse caleidoscópio de análises contribuiu para a disseminação de desconfianças e conflitos.

"A cloroquina foi uma droga candidata, e já se mostrou que ela não funciona. Isso é um consenso internacional. No Brasil, todas as sociedades médicas e científicas concordam com o consenso internacional. Por que apenas o Ministério da Saúde está indo contra esse consenso internacional e nacional (...)?” (Natalia Pasternak Taschner, Instituto Questão de Ciência, Instituto de Ciências Biomédicas, Universidade de São Paulo - USP, 14/Jul/2020).

"Então, não há consenso nacional ou internacional. Essa é uma palavra um pouco forte. (...) Existem, sim, evidências - e o Daniel colocou isso de forma muito interessante - contra e a favor. Acho um pouco arriscado desmerecer todas as evidências. Temos que trabalhar com as melhores evidências no momento, numa situação crítica e emergencial. Mas, enfim, é uma discussão científica. E a discussão científica não termina aqui, não vai terminar tão cedo" (Hélio Angotti Neto, Ministério da Saúde, 14/Jul/2020).

Para além de um "debate técnico", na contenda entre as coalizões, não apenas valores relativos às evidências cientificas estão em disputa, mas também posições político-partidárias. Fica claro que apoiar a cloroquina é se posicionar como aliado do governo, e, portanto, sobre essa decisão também recaem interesses e objetivos políticos.

"Dr. Luiz, eu ouvi atentamente toda essa discussão. Sou a favor do Presidente Jair Messias Bolsonaro, sou do PSL e sou uma defensora da cloroquina e da hidroxicloroquina" (Deputada Soraya Manato, PSL-ES, 14/ $\mathrm{Jul} / 2020)$. 


\section{Figura 1}

Diagrama da estrutura das coalizões para a política terapêutica da cloroquina na Comissão Externa da Câmara dos Deputados destinada a acompanhar o enfrentamento à pandemia da COVID-19 no Brasil (CEXCORVI).

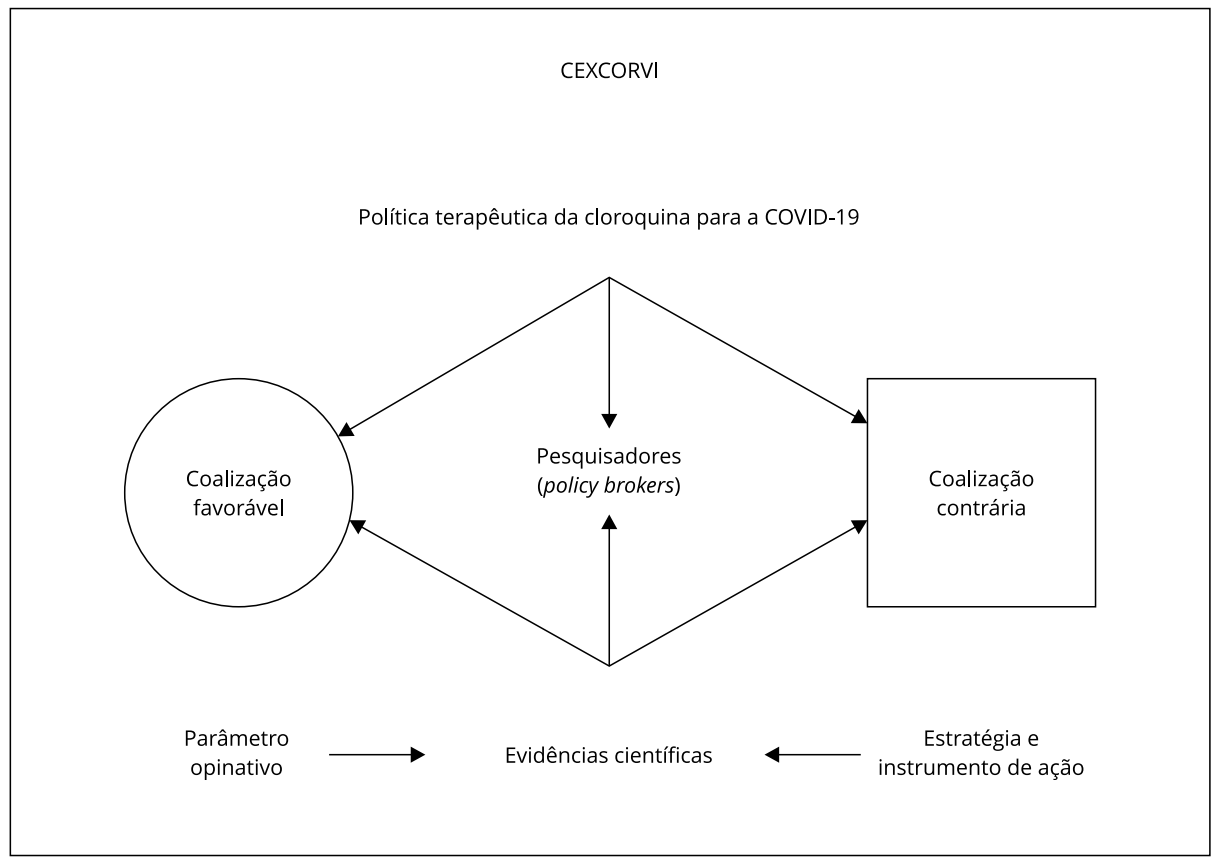

Fonte: elaboração da autora.

\section{Figura 2}

Mapa de posições e crenças sobre as evidências científicas entre os atores da Comissão Externa da Câmara dos Deputados destinada a acompanhar o enfrentamento à pandemia da COVID-19 no Brasil (CEXCORVI).

\begin{tabular}{|c|c|c|c|c|c|c|c|c|c|c|}
\hline \multirow[t]{4}{*}{$\begin{array}{c}\text { Autoridade } \\
\text { Relativa }\end{array}$} & \multicolumn{2}{|c|}{ Convicção } & $\begin{array}{l}\text { Baseada na } \\
\text { experiência }\end{array}$ & \multirow[t]{4}{*}{ Flexível } & \multicolumn{2}{|c|}{$\begin{array}{c}\text { Força } \\
\text { Normativa }\end{array}$} & \multicolumn{2}{|c|}{$\begin{array}{c}\text { Rigor e } \\
\text { Cientificidade }\end{array}$} & \multicolumn{2}{|c|}{ Superioridade } \\
\hline & DK & EP & & & & & & & DK & EP \\
\hline & $\mathrm{JC}$ & JF & & & DK & EP & $\mathrm{JC}$ & JV & JF & AP \\
\hline & NP & $\mathrm{AP}$ & & & JV & AP & & & & \\
\hline
\end{tabular}

AD: Albert Dickson; AP: Alexandre Padilha; CD: Carla Dickson; CN: Ceuci Nunes; DK: Daniel Knupp; EP: Estevão Portela; FS: Fernando Suassuna; GP: General Peternelli; HA: Hélio Agnotti; HG: Hiran Gonçalves; JC: Julio Croda; JF: Jandira Feghali; JV: João Viola; NP: Natalia Pasternak; PB: Paula Belmonte; SM: Soraya Manato. 
Por fim, é o CFM que, ao reivindicar voz autoritativa frente à classe médica, estabiliza os contornos da terapêutica para a COVID-19 ao conferir salvaguarda ao médico assistente e a força de sua decisão clínica. Amparado em uma "lógica da pandemia", o defensor máximo da boa prática médica colocou, em suspeição, os próprios ditames da ética do medicamento 23.

"Como o Conselho Federal de Medicina nos dá autonomia de prescrever e o paciente tem autonomia de aceitar ou não a prescrição - também há o lado do paciente -, eu continuo com a prerrogativa de que realmente precisamos salvar vidas” (Deputado Estadual Albert Dickson, PROS-RN, 14/Jul/2020).

\section{Discussão}

\section{Negacionismo e a classe médica}

A arena de posições em relação ao estatuto de eficácia da cloroquina para o tratamento da COVID-19 coloca, em debate, o uso da incerteza científica como forma de produzir dissenso e assim sustentar convicções pessoais e ideologias. Como retrata Stengers 24, a ciência, a modo de qualquer projeto social, não se descola dos interesses do mundo, e seus intérpretes são, antes de tudo, membros de uma comunidade e não seres racionais e lúcidos. Portanto, eles manipulam ativamente esse universo para fazer prevalecer suas teses, ao tempo em que escondem suas próprias estratégias, que visam "criar uma diferença nas controvérsias que o opõem aos seus rivais” 24 (p. 19). Assim, sob a égide dessa incerteza produzida, legisladores e seus apoiadores conseguem suspender argumentos e mesmo consensos científicos para manter medidas de interesse.

O debate brasileiro sobre o lugar da cloroquina no tratamento da COVID-19 é um exemplo de como o negacionismo tem organizado a política atual. No campo científico, o negacionismo da ciência pode ser definido com um fenômeno que busca rejeitar proposições empiricamente sustentadas e de consenso científico para criar uma falsa aparência de debate, uma vez que esse é inexistente 25 . Dessa maneira, segundo Latour ${ }^{7}$, esse tipo de situação paralisa a política e empreende um debate que visa produzir a ideia de que há dois lados, utilizando o mesmo repertório da ciência versus a política. E é propriamente esse processo político que, segundo o autor, precisamos nos ater 9.

Na CEXCORVI, o objetivo de criar o convencimento de que não há motivos suficientes para rejeitar o uso da cloroquina como terapêutica para a COVID-19 atende, com precisão, todas as cinco características do negacionismo identificados por Diethelm \& McKee 26: presença de conspirações; uso de falsos especialistas ou difamação de pesquisadores; seletividade; desvalorização das pesquisas em referência aos seus limites empíricos e incerteza intrínseca; uso de deturpações e falácias lógicas.

Ser contra a cloroquina não marca uma posição frente ao uso racional de medicamentos (definido pela Organização Mundial da Saúde 27 como a situação na qual o paciente recebe uma medicação apropriada para suas necessidades clínicas, nas doses individualmente requeridas para um adequado período de tempo e a um baixo custo para ele e para a comunidade), mas conspira contra o próprio governo e seu sucesso no enfrentamento da pandemia. E como a coalizão contrária à cloroquina também se posicionava politicamente como oposição ou independentes, foi fácil descolar os argumentos de uma base científica para uma oposição pessoal. O próprio presidente, em uma de suas comunicações em redes sociais, expressou que: "quem é de direita toma cloroquina, quem é de esquerda, Tubaína". Ademais, pesquisadores cujos trabalhos revelaram resultados em desfavor da cloroquina foram também retratados como conspiradores. Em um exemplo ilustrativo desse cenário, uma pesquisa conduzida por um consórcio de instituições - a CloroCovid-19 - instalou uma intensa disputa de verdades e narrativas, culminando em uma ofensiva dirigida aos pesquisadores, com ameaças e perseguições, ao serem divulgados seus achados iniciais que informavam sobre o risco de toxicidade com o uso de doses elevadas desse medicamento 28,29.

A força política dos negacionistas que ocupavam tanto o espaço da CEXCORVI quanto os órgãos de governo produziu uma ancoragem política que se sustentava tanto em uma legitimidade profissional (médicos) quanto pelo poder conferido por seus cargos na administração pública. Agindo como verdadeiras máquinas de guerra 7, o conjunto desses atores políticos buscou ocupar posições privilegiadas com relação aos demais intérpretes da ciência. E a agir de forma a modelar aos fatos científicos, estabelecendo uma relação social de força, como juiz e único espírito crítico capaz de congregar 
ciência e humanidade, os seus contendores eram descritos como excessivamente entregues aos fatos e à objetividade científica, agindo assim em desfavor ao controle precoce da pandemia.

Adicionalmente, externamente à CEXCORVI, a estratégia negacionista conseguiu angariar um grupo privilegiado de especialistas - a classe médica, que foi fundamental para antagonizar o debate político. Se a ciência já estava impregnada por um tipo de "politização", que a impedia de ser uma conselheira neutra e racional, o discurso liberal logo avançou para o campo da relação médico-paciente, que restava como um espaço privilegiado de decisão e pactuação de riscos e benefícios com "independência" aos desmandos políticos. Desse modo, apoiados pelo seu órgão máximo - o CFM, a classe médica pode ser considerada o elo decisivo para a consolidação da narrativa presidencial e a difusão generalizada dessa medicação. Um estudo de Correia e colaboradores demonstrou que a propensão em prescrever a cloroquina entre os médicos brasileiros foi alta, variando entre 37-89\%, segundo a severidade da doença 30 . Como reforça Labra 31 , as organizações médicas ocupam um lugar de destaque no direcionamento das políticas de saúde e são capazes de remodelar estruturas acomodando assim seus próprios interesses. Essas observações são também compartilhadas por diferentes autores como Menicucci 32, Viana \& Silva 33 e Côrtes 34 .

\section{Evidências que não orientam condutas}

O debate da cloroquina se reproduz em um cenário em que a ciência é usada contra a própria ciência. De um lado, favorecer a cloroquina é valorizar o próprio sistema produtivo nacional, já amplamente adaptado à produção em larga escala desse medicamento, mas que não encontra respaldo científico suficiente. Por outro, a busca por opções terapêuticas baseadas em evidências científicas não atende à conveniência política. A experiência clínica apesar de advir de observações clínicas criteriosas sofre severas limitações, já que não inclui situações controladas. Isso posto, é impossível saber se o sucesso terapêutico proveio de efeito placebo, regressão à média, remissão espontânea ou variabilidade individual de sinais e sintomas. Portanto, essa conduta não é passível de generalização 35. Já as evidências externas, geradas por pesquisas de alto nível, exigem um engajamento sistemático de pesquisadores, que demandam elevados recursos financeiros para condução de suas pesquisas (no caso brasileiro altamente dependentes de financiamento público) e que notadamente padecem com o descaso e o desmerecimento por parte do Governo Federal 36,37.

Sobre essa campanha para descredibilizar instituições e cultivar a desinformação, Caponi 38 chama a atenção para a crescente aceitação, também no meio social, do negacionismo científico e a desconsideração de pesquisadores e das universidades. Para a autora, foi esse negacionismo que possibilitou a aceitação de intervenções sem validação científica, como o caso da cloroquina. Nesse contexto, é essencial compreender o papel do ceticismo e da crítica que, desvirtuados de seus sentidos originais, enquanto uma parte da lógica que trata do julgamento com o intuito de aferir ou propor novas ideias, passam a se destacar pela proliferação de incertezas e dúvidas infundadas. Modelo de pensamento estratégico para a ascensão da extrema direita no mundo, não foi ao acaso que os maiores defensores do uso disseminado da cloroquina para o tratamento da COVID-19 foram líderes populistas Donald Trump e Jair Bolsonaro.

Assim, o negacionismo científico possui um papel determinante na construção de valores à cloroquina ao produzir a dúvida com o propósito de persuadir o processo de desenvolvimento de políticas públicas. Deturpando o entendimento público sobre a ciência e seus procedimentos, a contestação dos argumentos científicos é moldada a partir de métodos não experimentais ou de baixa qualidade metodológica, mas que foram defendidos ou mesmo conduzidos por parte dos legisladores e seus interlocutores. A disseminação de achados que promovem a desinformação, a despeito de advogar contra a própria definição de evidência, que se refere àquilo que é efetivo ${ }^{39}$, foi capaz de construir valores positivos à cloroquina, dada a desconfiança dirigida à competência dos pesquisadores e especialistas. Atuando em um plano operacional distinto da construção das evidências científicas, o debate da cloroquina reproduz o mesmo roteiro de outros exemplos clássicos de ceticismo, como as campanhas enganosas da indústria do tabaco 40 e a negação da crise climática 9,41. Sustentando narrativas de uma ausência de consenso científico, esses mercadores da dúvida 40 defendem a cloroquina não com base no seu efeito farmacológico, mas a partir da dúvida sobre o seu efeito. E demonstram que o negacionismo não se ampara em um tipo de analfabetismo científico, ao contrário, usurpa o próprio 
modelo científico para produzir desinformação e criar falsos debates acerca das evidências. E como a própria ciência se alimenta de controvérsias, os negacionistas se aproveitam dessa vulnerabilidade (que tanto pode impulsionar quanto deturpar) para criar uma impressão de que nada está resolvido e assim conseguir minar a realidade do conhecimento científico 40.

\section{Considerações finais}

A consolidação de um projeto de confusão atordoante encontrou, na CEXCORVI, um palanque para a dúvida e ratificou a ideia de que havia dois lados para a cloroquina na disputa pela terapêtica da COVID-19. Assim, na análise da construção da política terapêutica da cloroquina, fica claro como o debate político se orienta pela exploração contundente da dúvida. Um lado busca demonstrar o seu convencimento no consenso científico contrário à cloroquina, e o outro nega a existência de tal entendimento. E frente ao desprezo governamental com relação a outras medidas de controle da pandemia (como o distanciamento social), o uso extensivo da cloroquina é conclamado como conduta de excelência e elemento comprobatório da ação do Estado contemporâneo: escapando da necessidade de comprovação de seus atos para, no lugar, encenar acomodações contingenciais, capazes de estabilizar um fato não em meio a certezas, mas pelo medo da dúvida.

\section{Informação adicional}

ORCID: Thais Rodrigues Penaforte (0000-00033606-7453).

\section{Referências}

1. World Health Organization. A year without precendent: WHO's COVID-19 reponse. https://www.who.int/news-room/spotlight/ayear-without-precedent-who-s-covid-19-re sponse (acessado em 27/Jan/2021).

2. Brasil. Constituição da República Federativa do Brasil de 1988. http://www.planalto.gov. br/ccivil_03/constituicao/constituicao.htm (acessado em 27/Jan/2021).

3. Brasil. Lei no 13.979, de 6 de fevereiro de 2020. Dispõe sobre as medidas para enfrentamento da emergência de saúde pública de importância internacional decorrente do coronavírus responsável pelo surto de 2019. Diário Oficial da União 2020; 7 fev.

4. Câmara dos Deputados. Comissão Externa destinada a acompanhar as ações preventivas da Vigilância Sanitária e possíveis consequências para o Brasil quanto ao enfrentamento da pandemia causada pelo coronavírus. https://www2.camara.leg.br/atividade-leg islativa/comissoes/comissoes-temporarias/ externas/56a-legislatura/enfrentamento-pan demia-covid-19/outros-documentos/planode-trabalho (acessado em 26/Jun/2021). 
5. Deubel AR. Políticas públicas: formulación, implementación y evaluación. Bogotá: Aurora; 2007.

6. Ham C, Hill MJ. O processo de elaboração de políticas no Estado capitalista modern. In: Hill MJ, editor. The policy process: a reader. New York; London: Harvester Wheatsheaf; 1993. p. 39-70.

7. Latour B. Para distinguir amigos e inimigos no tempo do Antropoceno. Revista de Antropologia 2014; 57:11-31.

8. Latour B. Políticas da natureza. Como fazer ciência na democracia. Bauru: EDUSC; 2004.

9. Latour B. Onde aterrar? Como se orientar politicamente no Antropoceno. Rio de Janeiro: Bazar do Tempo; 2020.

10. Andrade AM, Coutinho RLF. Processo Legislativo nas comissões da Câmara dos Deputados. Brasília: Câmara dos Deputados; 2019.

11. Capella ACN, Brasil FG. Subsistemas, comunidades e redes: articulando ideias e interesses na formulação de políticas públicas. Revista do Serviço Público 2015; 30:449-74.

12. Thurber JA. Political power and policy subsystems in American politics. In: Peters G, Rockman BA, editors. Agenda for excellence: administering the State. Chatham: Chatham House Publishers; 1996. p. 76-104.

13. Hull MS. Documents and bureaucracy. Annu Rev Anthropol 2012; 41:251-67.

14. Latour B. Why has critique run out of steam? From matters of fact to matters of concern. Crit Inq 2004; 30:225-48.

15. Sabatier PA, Weible CM. The advocacy coalition framework: innovations and clarifications. In: Sabatier PA, editor. Theories of the policy process. Boulder: Westview Press; 2007. p. $189-220$.

16. Muir Gray JA. Evidence-based healthcare: how to make health policy and management decisions. New York: Churchill-Livingstone; 1997.

17. Trump DJ (@realDonald Trump). HYDROXYCHLOROQUINE \& AZITHROMYCIN, taken together, have a real chance to be one of the biggest game changers in the history of medicine. Twitter 2020; 21 mar. https://twitter.com/realDonaldTrump/sta tus/124136723990077.

18. Gautret P, Lagier JC, Parola P, Hoang VT, Meddeb L, Mailhe M, et al. Hydroxychloroquine and azithromycin as a treatment of COVID-19: results of an open-label non-randomized clinical trial. Int J Antimicrob Agents 2020; 56:105949.

19. Bolsonaro JM (@jairbolsonaro). Temos informações precisas que a cloroquina tem sido usada pelo Brasil com uma grande taxa de sucesso. Twitter 2020; 27 mar. https://twitter.com/ jairbolsonaro/status/1243502255606824963.

20. Ministério da Saúde. Uso da Cloroquina como terapia adjuvante no tratamento de formas graves do COVID-19. Nota Informativa no 6/2020 - DAF/SCTIE/MS. https://por talarquivos.saude.gov.br/images/pdf/2020/ April/08/Nota-Informativa-06-CloroquinaDAF-SCTIE.pdf (acessado em 27/Jan/2021).
21. Ministério da Saúde. Orientações para manuseio medicamentoso precoce de pacientes com diagnóstico da COVID-19. Nota Informativa no 9/2020-SE/GAB/SE/MS. https:// sei.saude.gov.br/sei/controlador_externo. php?acao =documento_conferir\&codigo_ve rificador $=0014934763 \&$ codigo_crc $=9 \mathrm{D}$ F7CA1E\&hash_download $=4 \mathrm{~d} 41794470 \mathrm{c}$ c 484995 b 1 b 996 c6 63 ef 3816 fc 01 fe 919 d d 8 e 383 e 1268562 ebbffdb0ba $288641 \mathrm{fd}$ $358 \mathrm{~d} 848698 \mathrm{ac} 1 \mathrm{fba} 5 \mathrm{c} 18516 \mathrm{da} 7890 \mathrm{acd} 1 \mathrm{bce}$ f1b47b1001b74f7f4\&visualizacao $=1 \&$ id_or gao_acesso_externo=0 (acessado em 27/ Jan/2021).

22. TrateCOV: aplicativo auxilia médicos no diagnóstico da Covid-19. https://www.gov. $\mathrm{br} / \mathrm{casacivil} / \mathrm{pt}-\mathrm{br} / \mathrm{assuntos} /$ noticias/2021/ janeiro/tratecov-aplicativo-auxilia-medicosno-diagnostico-da-covid-19 (acessado em 25/ Jan/2021).

23. Wannmacher L. A ética do medicamento: múltiplos cenários. Temas Selecionados 2007; 4:1-6.

24. Stengers I. As ciências e seus intérpretes. In: Stengers I. A invenção das ciências modernas. São Paulo: Editora 34; 2002. p. 11-29.

25. Debunking science denialism. Nat Hum Behav 2019; 3:887.

26. Diethelm P, McKee M. Denialism: what is it and how should scientists respond? Eur J Public Health 2009; 19:2-4.

27. World Health Organization. Rational use of medicines: progress in implementing the WHO medicines strategy. https://apps.who. int/gb/ebwha/pdf_files/EB118/B118_6-en. pdf (acessado em 17/Mar/2021).

28. Borba MGS, Val FFA, Sampaio VS, Alexandre MAA, Melo GC, Brito M, et al. Effect of high vs low doses of chloroquine diphosphate as adjunctive therapy for patients hospitalized with severe acute respiratory syndrome coronavirus 2 (SARS-CoV-2) infection: a randomized clinical trial. JAMA Netw Open 2020; 3:e208857.

29. Neves ALM, Ferreira BO. Narrativas entre ciência e política no ativismo da Cloroquina. Psicol Soc 2020; 32:e020006.

30. Correia LC, Lopes JRO, Garcez FB, Le Campion E, Bracellos G, Barreto-Filho JA. Physicians' preference towards the non-evidence based hydroxychloroquine treatment for COVID-19: the pandemic effect. Journal of Evidence-Based Healthcare 2020; 2:10-5.

31. Labra ME. Associativismo no setor saúde brasileiro e organizações de interesse do empresariado médico. Physis (Rio J.) 1993; 3:193225.

32. Menicucci TMG. História da reforma sanitária brasileira e do Sistema Único de Saúde: mudanças, continuidades e a agenda atual. Hist Cienc Saúde Manguinhos 2014; 21:77-92.

33. Viana ALD, Silva HP. Relações Estado, mercado e sociedade no Brasil: arranjos assistenciais produtivos na saúde. In: Viana ALD, Ibñez N, Bousquat A, organizadores. Saúde, desenvolvimento, ciência, tecnologia e inovação. São Paulo: Hucitec Editora; 2012. p. 105-32. 
34. Côrtes SV. Sistema Único de Saúde: espaços decisórios e a arena política de saúde. Cad Saúde Pública 2009; 25:1626-33.

35. Wannmacher L. Quanto é evidente a evidência na saúde? Uso Racion. Medicam. Temas Selecionados 2006; 3:1-6.

36. Pivaro GF, Girotto Júnior G. O ataque organizado à ciência como forma de manipulação: do aquecimento global ao coronavírus . Caderno Brasileiro de Ensino de Física 2020; 37:107498.

37. The Lancet. COVID-19 in Brazil: "So what?". Lancet 2020; 395:1461.
38. Caponi S. Covid-19 no Brasil: entre o negacionismo e a razão neoliberal. Estud Av 2020; 34:209-24.

39. Parkhurst J. The politics of evidence. From evidence-based policy to the good governance of evidence. London/New York: Routledge; 2017.

40. Oreskes N, Conway EM. Merchants of doubt: how a handful of scientists obscured the truth on issues from tobacco smoke to climate change. New York: Bloomsbury Press; 2013.

41. Oreskes N. The scientific consensus on climate change. Science 2004; 306:1686. 


\section{Abstract}

The objective of this study was to analyze the positions and developments in the Brazilian Congress in an inquiry from March to August 2020 on policy for COVID-19 treatment using chloroquine. The analysis aimed to identify the factors situating this policy in the context of government action during the pandemic. The ethnographic artifacts used for the analysis included the videoconferences of the committee meetings and public hearings and the stenographic notes publicly available on the Chamber of Deputies website. The analysis showed that the debate on chloroquine was forged from scientific evidence used with a denialist perspective, prioritizing the search for uncertainty as a way of fomenting dissent and thus sustaining personal convictions and ideologies. By rejecting empirically backed proposals and scientific consensus itself, the attempt was to create a false appearance of debate. The objective was to convince the public that there were no sufficient grounds for rejecting the use of chloroquine to treat COVID-19. Thus, the success achieved by the government was not based on verification of truths, but as the result of a temporary accommodation that stabilized this purported fact not through certainties, but through fear of doubt.

Public Policy; Health Policy; COVID-19; Chloroquine

\section{Resumen}

El objetivo de este trabajo fue dar luz a los movimientos y despliegues que hubo, respecto a la politica terapéutica de la cloroquina, en el Parlamento brasileño, con el fin de identificar los factores que la situaron en el contexto de la acción pública contra la COVID-19. Las herramientas etnográficas utilizadas para este análisis incluyeron videoconferencias de las reuniones y audiencias públicas, así como notas taquigráficas disponibles públicamente en la sede de la Cámara de los Diputados. Como resultado, se observó que el debate de la cloroquina se forjó entre evidencias científicas utilizadas a partir de una perspectiva negacionista, que privilegió la búsqueda de la incertidumbre como forma de producir discrepancia, y así respaldar convicciones personales e ideologías. Al rechazar las propuestas defendidas empiricamente, así como el propio consenso científico, se buscaba crear una falsa apariencia de debate. El objetivo era instaurar el convencimiento de que no existen motivos suficientes para rechazar el uso de la cloroquina como terapia contra la COVID-19. De este modo, el éxito logrado por el gobierno no se produjo a partir de la verificación de verdades, sino que fue el resultado de un acomodo circunstancial, que dio por bueno ese hecho, no por sus certezas, sino por el miedo a la duda.

Política Pública; Política de Salud; COVID-19; Cloroquina
Recebido em 29/Jan/2021

Versão final reapresentada em 20/Abr/2021

Aprovado em 25/Jun/2021 